\title{
1 Correlation between the Barcelona test and the bending test in fibre reinforced
}

2 concrete

3

4 Eduardo Galeote $^{\mathrm{a}, *}$, Ana Blanco ${ }^{\mathrm{a}}$, Sergio H.P. Cavalaro ${ }^{\mathrm{a}}$, Albert de la Fuente

5

6 a Department of Civil and Environmental Engineering, Universitat Politècnica de

7 Catalunya Barcelona Tech, Jordi Girona 1-3, C1, 08034 Barcelona, Spain

8 * Corresponding author: Eduardo Galeote. Department of Civil and Environmental

9 Engineering, Universitat Politècnica de Catalunya Barcelona Tech, Jordi Girona 1-3,

10 C1, 08034 Barcelona, Spain. Email address: eduardo.galeote@ upc.edu

\section{Abstract}

The Barcelona test $(\mathrm{BCN})$ is an alternative method to characterize the post-cracking behaviour of fibre reinforced concrete (FRC). Given its simplicity, the reduced scatter of the results and low material consumption, the BCN may represent a suitable method for the quality control of FRC. For that, a correlation between the results of the BCN and the bending test is currently required since the latter is considered the reference for the characterization of the material and for deriving the constitutive design equations. The objective of this paper is to propose such correlation following an approach that takes into account the intrinsic variability of FRC. An experimental program involving 21 mixes of conventional and self-compacting FRC with either steel or plastic fibres was performed. Several analyses were conducted both for selecting the most relevant parameters and for maximizing the degree of correlation between the tests. The highest correlation coefficient between tests was obtained for the mixes with plastic fibres. In 
such case, the formulation proposed is able to predict the results with accuracy up to $75 \%$. The correlation found is an interesting tool towards a simple and reliable quality control of FRC based on the BCN mainly oriented to large scale concrete production.

Keywords: correlation; fibre reinforced concrete; Barcelona test; flexural test; scatter

\section{INTRODUCTION}

The quality control of fibre reinforced concrete (FRC) used in structural applications should include tests for the assessment of the post-cracking response of the material.

The selection of suitable testing methods for this purpose becomes particularly relevant given the high intrinsic scatter associated with the post-cracking response [1]. In this context, it is important to count with simple and fast methods that may provide enough repetitions for a reliable statistical analysis of the results that could lead to representative average and characteristic values of the post-cracking strength of the material.

The most extended method applied nowadays is the three-point bending test (3PBT) according to EN 14651:2007 [2]. It presents a coefficient of variation usually above $20 \%[3,4]$ and a complex setup if compared to other tests, requiring special equipment and relatively big specimens. For these reasons, as suggested by the Belgian standard NBN B 15-238 [5], the 3PBT is not considered suitable for the systematic quality control of FRC. Thereby, alternative tests were developed in an attempt to overcome the drawbacks previously mentioned [6-8]. In this context, the fib Model Code 2010 [9] allows the use of alternative tests to obtain the residual strength of FRC if appropriately 
correlated to the results of the 3PBT. Therefore, in case such correlations are achieved, the substitution of the bending test by an alternative approach may be accepted.

The use of correlations between concrete properties measured in different test methods is a common and widely accepted procedure, even when the cracking mechanisms involved in each of them are completely different. For example, equations relating the compressive strength and the tensile strength are present in the majority of structural concrete codes and guidelines. Moreover, several equations are available to transform the indirect tensile strength measured in the Brazilian Test into the indirect flexural strength measured with bending tests [10]. In the case of FRC, Minelli et al. [11] already proposed a correlation between the Round Panel Test and the UNI flexural test based on the energy released and the residual strength. Correlations between different typologies of tests also provide an opportunity for developing new simplified stresscrack width laws for FRC $[12,13]$.

Another alternative to characterize the tensile residual strength of FRC is the Barcelona test (BCN) proposed by Molins et al. [4] and included in the standard UNE 83515:2010 [14]. Recently, it has been improved by Pujadas et al. $[15,16]$ and a constitutive equation based on the results of the test was proposed by Blanco et al. [17]. The BCN is simpler than the 3PBT in terms of execution since $75 \%$ lighter specimens are used and no closed-loop is required. It also presents smaller scatter [15] with a coefficient of variation of the results below 13\% [4]. Despite these advantages, the use of the $\mathrm{BCN}$ for the characterization of FRC is hindered by the lack of correlations with the 3PBT. 
75 Taking that into account, the objective of this paper is to correlate the results of both

76 tests so the BCN may be used as a complementary method to characterize the properties

77 of FRC. The approach presented here aims to obtain simple and reliable correlations

78 taking into account the typical variability of the material. In this regard, the correlation

79 proposed represents a tool towards a simpler, faster and less expensive quality control

80 of FRC based on the BCN. This approach is in line with the fib Model Code 2010 and

81 may also serve as an example for future correlations with other tests applied to FRC.

82

83

\section{METHODOLOGY TO CORRELATE THE TESTS}

84

85 The approach proposed to determine the correlation between the $\mathrm{BCN}$ and the 3PBT

86 consists of three stages, as indicated in Fig. 1. In the first stage, an experimental

87 program with a wide variety of concrete types was performed. In the second stage,

88 linear regressions are performed considering different variables included in the study.

89 This helps determining whether a universal correlation between both tests is possible or

90 if different formulations are needed depending on the type of concrete, the type of fibre

91 or the fibre content. 


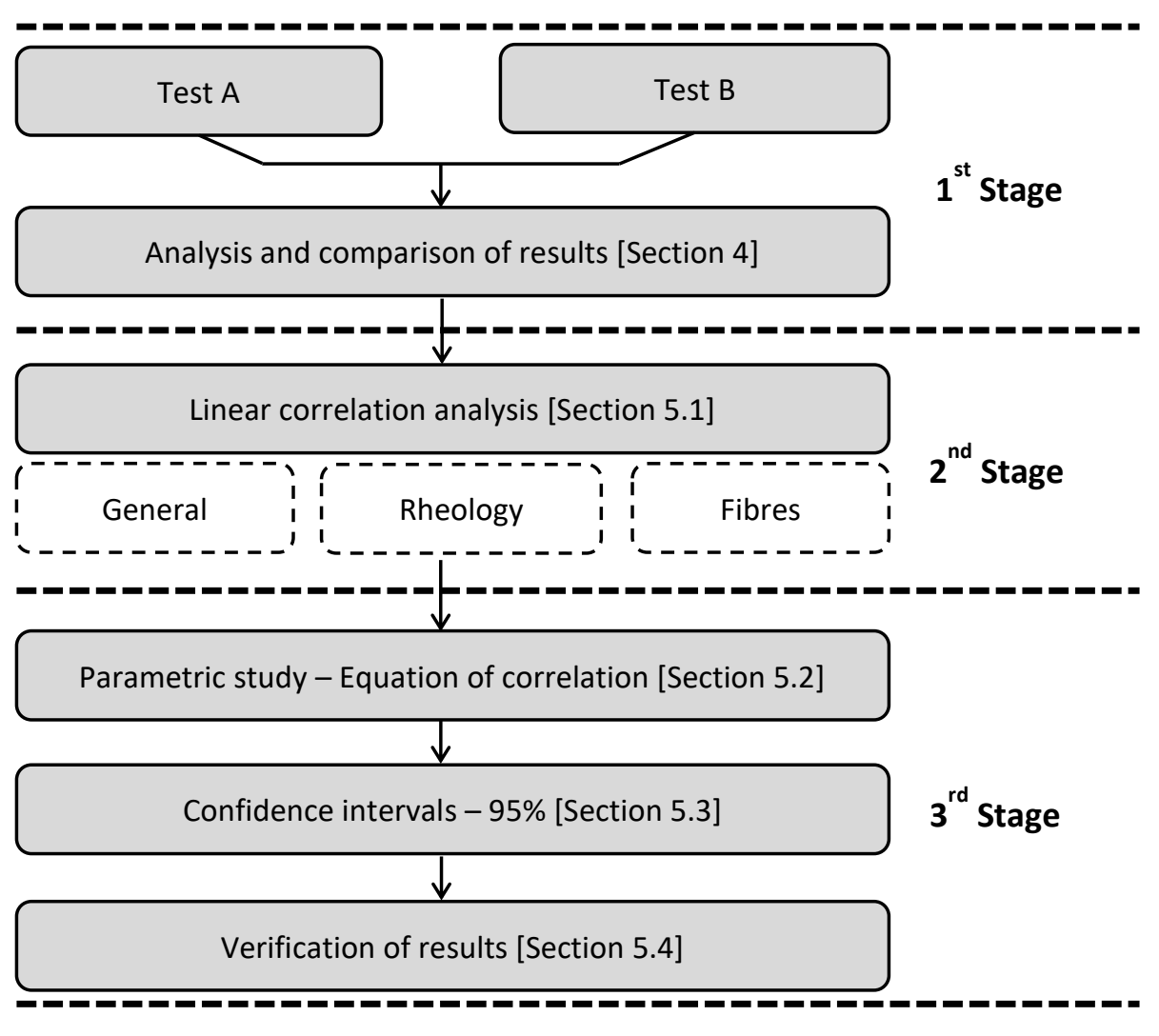

Fig. 1. Methodology used to derive the correlation between tests.

In the third stage a multi-variable parametric study is conducted in order to obtain the final correlations. To account for the variability of the FRC, an approach similar to that used in sprayed concrete is applied. Instead of proposing a single equation, a correlation zone defined by confidence intervals is derived through a statistical analysis of the results. Equations for the $50 \%$ and $95 \%$ confidence are proposed.

\section{EXPERIMENTAL PROGRAM}

\subsection{Materials and mixes}

Mixes with conventional concrete (CC) and self-compacting concrete (SCC) were 
107 it affects the orientation of the fibres [18-23]. In total, 21 concrete mixes were designed 108 with water-to-cement ratios ranging from 0.19 to 0.56 . Different types of cements were 109 used, with total contents between 275 and $700 \mathrm{~kg} / \mathrm{m}^{3}$. Hooked-end steel fibres (SF) were 110 added in contents from 30 to $60 \mathrm{~kg} / \mathrm{m}^{3}$, whereas the content of 3 types of plastic fibres 111 (PF1, PF2 and PF3) varied from 3.5 to $25 \mathrm{~kg} / \mathrm{m}^{3}$.

113 Table 1 summarizes the mixes depending on the main variables of the study. The

114 compressive strength in each mix is the average of 3 specimens of $\phi 150 \times 300 \mathrm{~mm}$ tested 115 under compression according to EN 12390-3 [24]. The nomenclature includes the type 116 of fibre and the content used. Table 2 shows the main characteristics of each type of 117 fibre.

\begin{tabular}{|c|c|c|c|c|c|}
\hline \multirow[b]{2}{*}{ Rheology } & \multirow{2}{*}{$\begin{array}{l}\text { Strength } \\
\text { Classificat. }\end{array}$} & \multirow{2}{*}{$\begin{array}{l}\text { Compressive } \\
\text { Strength }[\mathrm{MPa}]\end{array}$} & \multicolumn{2}{|l|}{ Fibre } & \multirow[b]{2}{*}{ Nomenclature } \\
\hline & & & Type & \begin{tabular}{|l|} 
Content \\
{$\left[\mathrm{kg} / \mathrm{m}^{3}\right]$}
\end{tabular} & \\
\hline \multirow{10}{*}{$\begin{array}{l}\text { Conventional } \\
\text { concrete (CC) }\end{array}$} & \multirow{4}{*}{$>60 \mathrm{MPa}$} & 66.4 & SF & 30 & CC_H60_SF_30 \\
\hline & & 65.1 & SF & 45 & CC_H60_SF_45 \\
\hline & & 66.2 & SF & 60 & CC_H60_SF_60 \\
\hline & & 85.0 & PF3 & 25 & CC_H60_PF3_25 \\
\hline & \multirow{6}{*}{$<60 \mathrm{MPa}$} & 47.7 & PF1 & 4 & CC_L60_PF1_4 \\
\hline & & 46.1 & PF1 & 6 & CC_L60_PF1_6 \\
\hline & & 48.1 & PF1 & 8 & CC_L60_PF1_8 \\
\hline & & 51.6 & PF2 & 4 & CC_L60_PF2_4 \\
\hline & & 52.9 & PF2 & 6 & CC_L60_PF2_6 \\
\hline & & 52.5 & PF2 & 8 & CC_L60_PF2_8 \\
\hline \multirow{11}{*}{$\begin{array}{l}\text { Self- } \\
\text { compacting } \\
\text { concrete } \\
\text { (SCC) }\end{array}$} & \multirow{6}{*}{$>60 \mathrm{MPa}$} & 71.9 & SF & 30 & SCC_H60_SF_30 \\
\hline & & 67.6 & SF & 45 & SCC_H60_SF_45 \\
\hline & & 60.2 & SF & 50 & SCC_H60_SF_50 \\
\hline & & 66.9 & SF & 60 & SCC_H60_SF_60 \\
\hline & & 82.6 & PF3 & 10 & SCC_H60_PF3_10 \\
\hline & & 77.2 & PF3 & 20 & SCC_H60_PF3_20 \\
\hline & \multirow{5}{*}{$<60 \mathrm{MPa}$} & 50.1 & SF & 50 & SCC_L60_SF_50A \\
\hline & & 40.4 & SF & 50 & SCC_L60_SF_50B \\
\hline & & 34.4 & SF & 50 & SCC_L60_SF_50C \\
\hline & & 57.4 & PF1 & 3.5 & SCC_L60_PF1_3.5A \\
\hline & & 52.4 & PF1 & 3.5 & SCC_L60_PF1_3.5B \\
\hline
\end{tabular}

Table 1. Main characteristics of the mixes. 


\begin{tabular}{lllll}
\hline Properties & SF & PF1 & $\boldsymbol{P F 2}$ & PF3 \\
\hline Material & Steel & Polypropylene & Polypropylene & Polyvinyl alcohol \\
Elastic Modulus [GPa] & 500 & 4.0 & 4.8 & 8.5 \\
Tensile strength [MPa] & 1000 & 400 & 338 & 800 \\
Length [mm] & 50 & 48 & 40 & 12 \\
Diameter [mm] & 1.00 & 0.84 & 0.75 & 0.20 \\
Aspect ratio [-] & 50 & 57 & 53 & 60 \\
\hline \multicolumn{5}{l}{ Table 2. Fibres characteristics (data provided by the manufacturers). }
\end{tabular}

121

\subsection{Specimens and test procedure}

As shown in Fig. 2, the BCN consists of a double punch test on a cylindrical $(\phi 150 \mathrm{~mm}$

$\mathrm{x} 150 \mathrm{~mm})$ or cubic $(150 \mathrm{~mm})$ specimen. The test is performed by placing,

concentrically above and below the specimen, cylindrical steel punches with a height of

$25 \mathrm{~mm}$ and a diameter equal to $1 / 4$ of the smaller dimension of the cross-section of the

specimen. The hydraulic press applies a load to the punches at a constant displacement

rate of $0.5 \pm 0.05 \mathrm{~mm}$ per minute. In the process, a conical triaxial state is formed from the centre to the edges of the specimen, leading to internal tensile stresses that increase with the load. Cracks appear (Fig. 2) when the stresses reach the tensile strength of the concrete matrix. After that, the fibres bridge the crack, providing a residual strength.

The results obtained may be represented through a Load-Total Circumferential Opening Displacement (TCOD) curve or Load-Axial Displacement relationship depending on the equipment used in the test, as depicted in Fig. 2. 


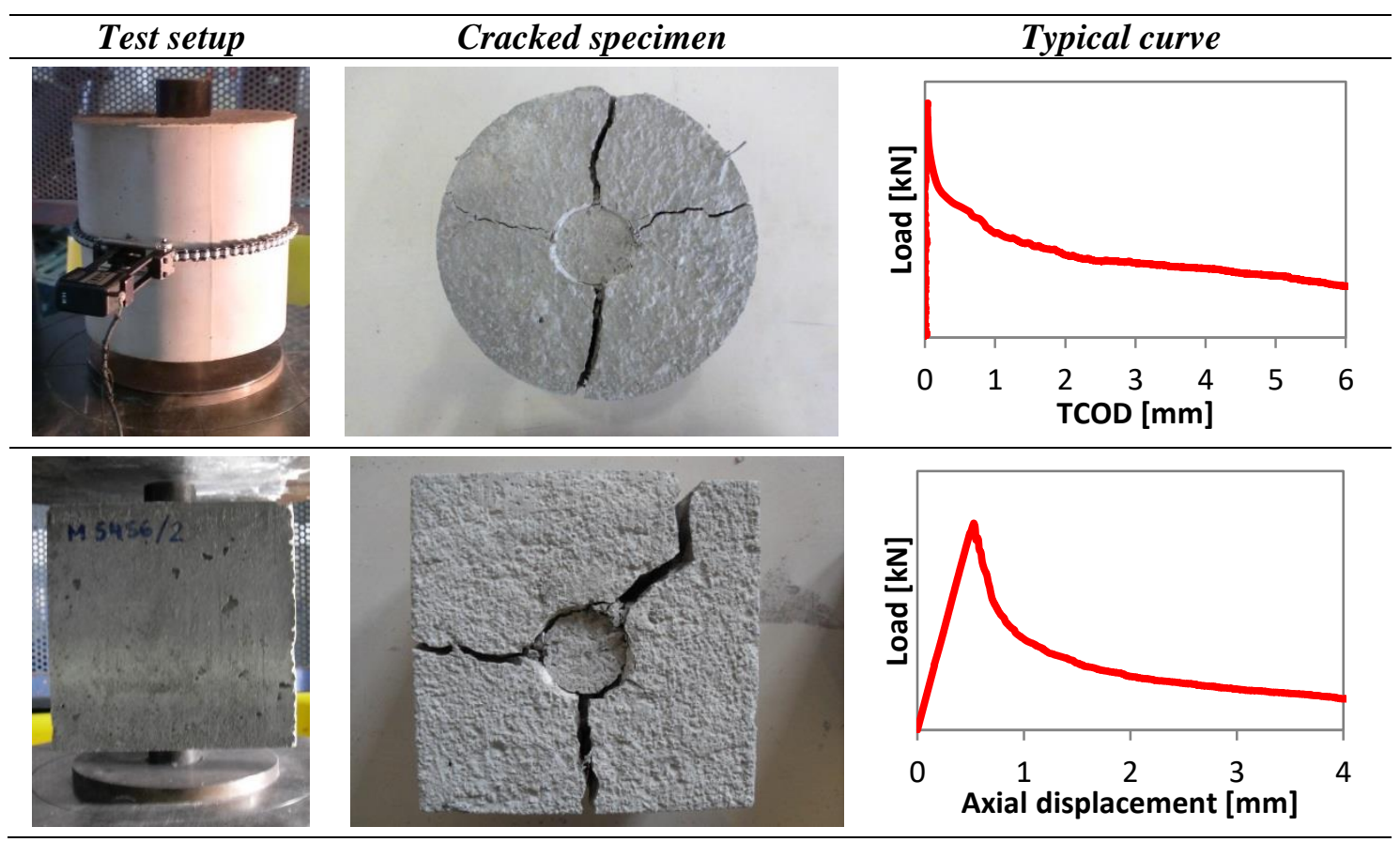

141

Fig. 2. BCN in cylindrical and cubic specimens.

144 The main difficulties to obtain acceptable correlations lay on the differences in the crack mechanism observed in both tests and, especially, the high variability intrinsic to the FRC. The fracture mechanism of the 3PBT is purely dominated by Mode I, while in the $\mathrm{BCN}$ the propagation of the crack is a mixed response between Modes I and II. This is shown in Fig. 3, which shows how the penetration of the two cones into the specimen (Mode II) produces the opening of several radial cracks where tensile stresses appear perpendicular to the fracture surface (Mode I). 

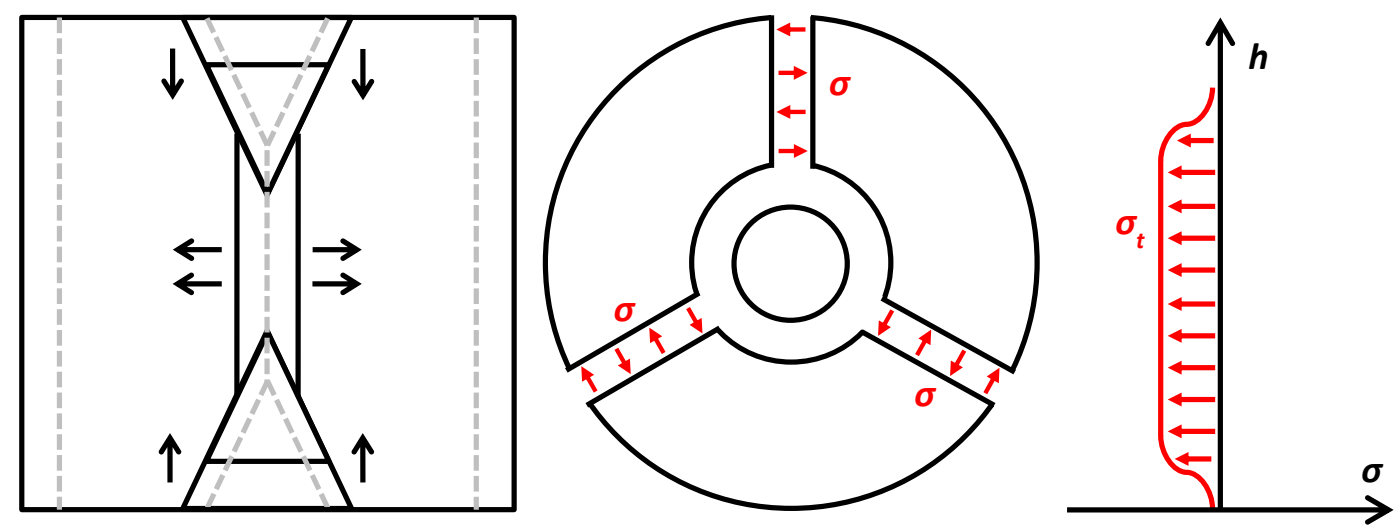

Fig. 3. Cracking mechanism and distribution of stresses.

Even though the failure mechanisms between 3PBT and the BCN might be different,

this should not pose a problem to obtain a correlation between both tests. In fact, several

codes and studies from the literature propose correlations between the results of test

methods with completely different cracking mechanisms (for example, between

compressive and tensile strength or between tensile and flexural strength, among others).

For all mixes produced here, 2 shapes of moulded specimens were manufactured: 72 beams of $150 \times 150 \times 600 \mathrm{~mm}$ for the 3PBT (according with the EN 14651:2007) and 72 cubes of $150 \mathrm{~mm}$ of side for the BCN. Once the 3PBT were concluded, each beam was cut in order to obtain 150 x $150 \mathrm{~mm}$ cubic specimens, resulting in 144 additional samples for the BCN test. As depicted in Fig. 4, these cuts were performed disregarding the first $50 \mathrm{~mm}$ from the extremities of the beam - in order to avoid the influence of the wall effect - and the central $200 \mathrm{~mm}$ - to avoid the influence of the crack produced during the 3PBT. 


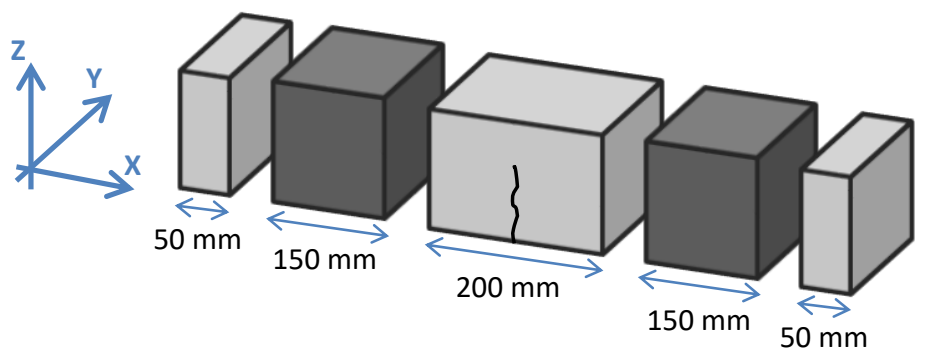

Fig. 4. Cubic specimens cut from the beams.

174 After that, the inductive test $[25,26]$ was conducted in moulded and cubic specimens

175 with included steel fibres. In this test, a coil is used to measure the content and preferential orientation of the fibres in the axes perpendicular to the faces of the specimens. The convention from Fig. 4 was adopted. According to this convention, the Z-direction is always parallel to the concrete casting direction. In the cut specimens, the $\mathrm{X}$-direction is parallel to the length of the beam. In moulded specimens, the directions $\mathrm{X}$ and $\mathrm{Y}$ are defined indistinctly since, in principle, no in-plane preferential direction is evident. Finally, the BCN (Fig. 2) was performed as described in this section in all cubic specimens. The direction of loading was parallel to the casting direction (Z). The force measured during the test was converted into stress following the equations proposed by [14].

\section{ANALYSIS AND COMPARISON OF THE RESULTS}

A preliminary analysis of the results is conducted to evaluate the influence of the variables from the study and the need to include them in the correlation. Even though other variables were also analysed, this section only describes the influence of the content of fibres, the rheology (conventional or self-compacting) and the type of cubic specimen (moulded or cut). 


\subsection{Influence of the fibre type} the $\mathrm{BCN}$ results.

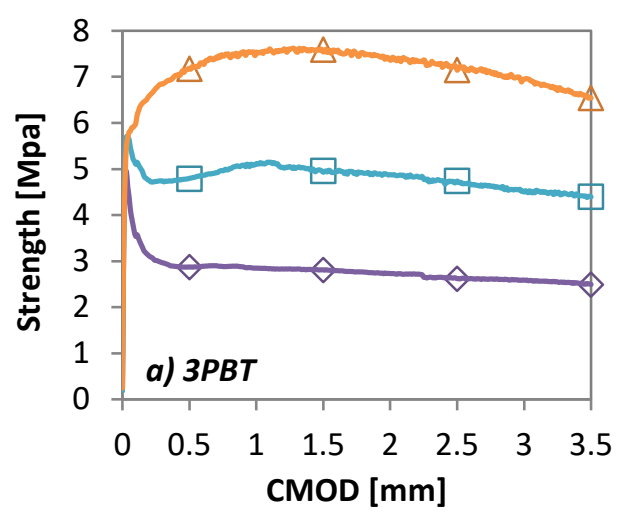

The differences between steel and plastic fibres in the mechanical response of FRC have been extensively described in literature [27-31] and are not the objective of this paper.

Rather than that, the results of the 3PBT and the BCN for different contents of SF are compared. The influence of the contents is depicted in Fig. 5 in a plot Load-Crack Mouth Opening Displacement (CMOD) for the 3PBT and Load-Axial Displacement for

The results from the $3 \mathrm{PBT}$ and $\mathrm{BCN}$ show a similar variation with the fibre content. In other words, higher stresses are resisted as the fibre content increases. The strength obtained in the $\mathrm{BCN}$ is in general lower than the strength observed in the 3PBT. This was more remarkable in dosage SCC_H60_SF_60 with $60 \mathrm{~kg} / \mathrm{m}^{3}$ of fibres, which was the only one to present hardening in the 3PBT after the first crack appeared. Conversely, none of the dosages presented hardening behaviour in the BCN.

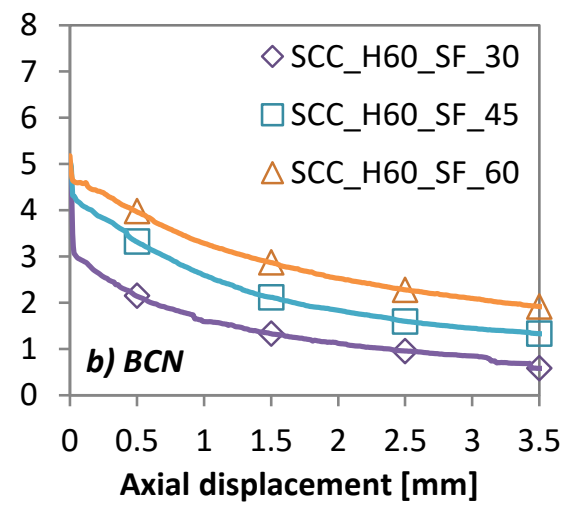


211 This outcome may be attributed to the differences between the cracking mechanisms in each test. Previous studies showed that the same FRC may present hardening in bending tests and softening in direct tension tests [32]. In the former, the crack length increases gradually due to the formation of a par with compression stresses provided by the unaffected concrete matrix and tensile stresses provided by the fibre bridging the cracks. Conversely, in the direct tension tests, the cracks tend to form abruptly, almost eliminating the contribution of the concrete matrix that has to be resisted by the fibres at this moment. In this context, a change of stiffness is more likely to occur, being observed as a drop in the stresses resisted just after cracking. Notice that the mechanism developed in the $\mathrm{BCN}$ is closer to that found in the direct tension test than in the bending test since cracks appear abruptly and the contribution of concrete is hindered.

Another factor that could explain the lower stresses found in the $\mathrm{BCN}$ in comparison with the 3PBT is the effective number and orientation of fibres bridging the cracks. In the $\mathrm{BCN}$, between 2 and 4 cracks are formed during the test. Usually the cracks with lower contribution of fibre tend to open more than others with higher fibre contribution. Therefore, the stresses measured become influenced by the overall in-plane fibre orientation instead of being a result of a single cracking plane that tend to be perpendicular to the direction with higher contribution, such as in the 3PBT.

\subsection{Influence of the rheology}

Fig. 6 shows the average residual strengths measured with 13 specimens tested under the $\mathrm{BCN}$ and 3 specimens tested by means of the 3PBT for each of the two equivalent mixes of conventional and self-compacting concrete: CC_H60_SF_45 and 
SCC_H60_SF_45, respectively. The scatter of the results is also shown using the

237

238

239

240

241

242

243

244

245

coefficient of variation $(\mathrm{CV})$ represented at the right vertical axis. Notice that both mixes present the identical nominal fibre type and content, as well as similar average compressive strength.

Immediately after cracking occurs in the 3PBT, the average residual strength of CC_H60_SF_45 is higher than that of SCC_H60_SF_45. As the crack opening grows, the trend is inverted and the performance of SCC_H60_SF_45 is greater than CC_H60_SF_45. By the typical scatter of the 3PBT, the results of the flexural test may be considered approximately the same. This conclusion is also derived from the analysis of the results from the $\mathrm{BCN}$, which shows approximately the same residual strength for SCC_H60_SF_45 and SCC_H60_SF_45 throughout the test.

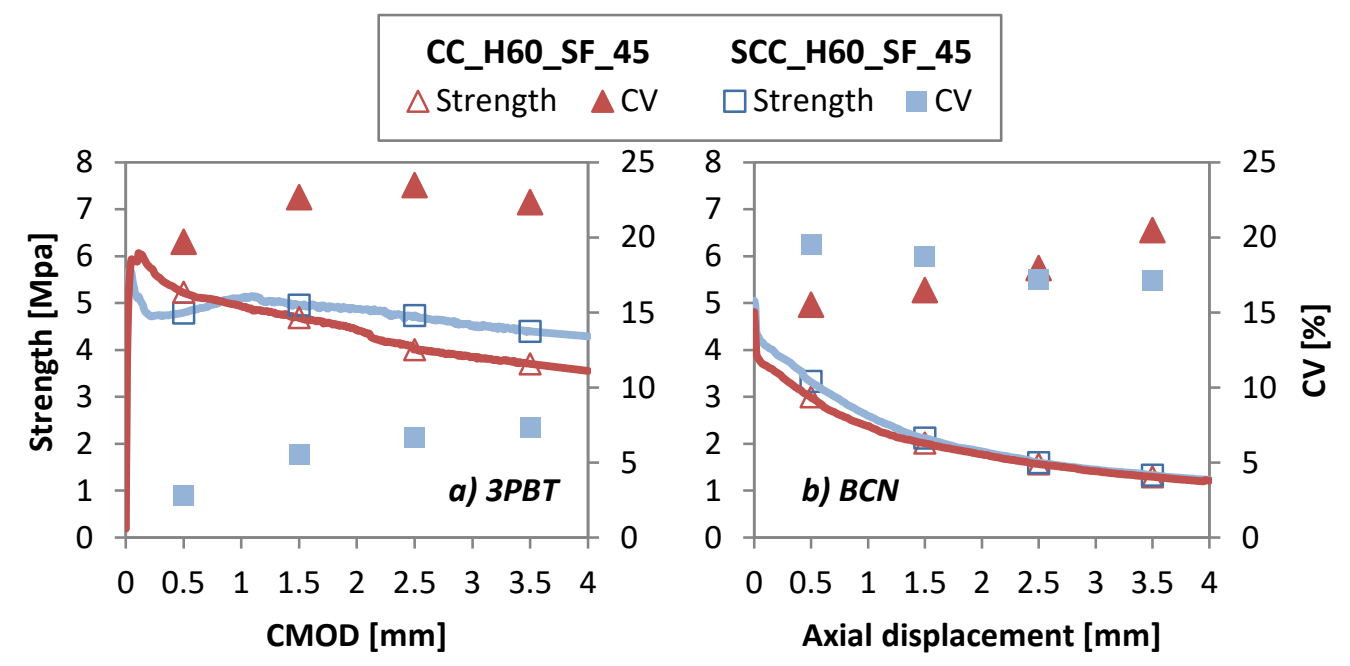

Fig. 6. Influence of the rheology in the results of the a) $3 P B T$ and the b) $B C N$.

The similarities of the residual response of both types of concrete may be explained by the fibre orientation. In the specimens cut from the beams tested with the 3PBT, the contribution of fibres in the X-direction is $41.5 \%$ for conventional concrete and $43.2 \%$ for self-compacting concrete. It is evident that, in spite of the change in rheology, small 
variations in terms of fibre orientation are observed in the main direction characterized in this 3PBT. Likewise, the contribution of fibres in the plane XY in moulded specimens tested with the $\mathrm{BCN}$ is approximately $80 \%$ regardless of the type of concrete. All these results justify the similarities between conventional and self-compacting concrete assessed in this study.

\subsection{Influence of the type of cubic specimen}

The manufacturing procedure of the two types of cubic specimen (cast and cut from the beam) may affect both the orientation and the mechanical performance. For this reason, the fibre orientation and the mechanical performance of both types of specimen is assessed and compared in order to know whether they may be used indistinctly for the assessment of the correlation. Table 3 shows the average orientation measured with the inductive test and the corresponding coefficient of variation (CV) in both types of specimen calculated for the 10 dosages with different contents of steel fibres.

Illustrative schemes of the preferential orientation measured are also presented.

\begin{tabular}{|c|c|c|c|c|c|c|c|}
\hline \multirow{2}{*}{$\begin{array}{l}\text { Type of } \\
\text { specimen }\end{array}$} & \multicolumn{2}{|l|}{$X$-axis } & \multicolumn{2}{|l|}{ Y-axis } & \multicolumn{2}{|l|}{ Z-axis } & \multirow{2}{*}{$\begin{array}{l}\text { Scheme of } \\
\text { orientation }\end{array}$} \\
\hline & Orientation & $C V$ & Orientation & $C V$ & Orientation & $\mathrm{CV}$ & \\
\hline Cut & $46.5 \%$ & $5.6 \%$ & $33.1 \%$ & $7.0 \%$ & $20.4 \%$ & $6.9 \%$ & \\
\hline Moulded & $38.9 \%$ & $3.5 \%$ & $38.9 \%$ & $3.0 \%$ & $22.2 \%$ & $8.6 \%$ & 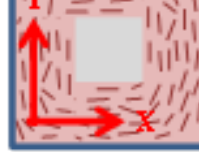 \\
\hline
\end{tabular}

Table 3. Average values and CV of the fibre contribution for cut and moulded specimens. 
274 Approximately $80 \%$ of the contribution of the fibres is concentrated in the plane

275 perpendicular to the casting direction in both types of specimens. This may be explained

276 by the flow and the external vibration applied in some of them during the production,

277 which favour a fibre alignment parallel to the XY plane [18, 20, 33-35].

278

279 In cut specimens, $46.5 \%$ of the contribution of the fibres is concentrated in X while only

$28033.1 \%$ of the contribution is observed in Y. This contrasts with the results from the

281 moulded specimens, which display almost the same contribution of fibres in $\mathrm{X}$ and in $\mathrm{Y}$.

282 Interestingly, the scatter for the measurements in both directions for cut specimens is

283 around twice as high as the calculated for moulded specimens (see CV in Table 3).

285 All these differences may be attributed to the influence of the shape of the specimens, the wall-effect and the flow of concrete during the production process. In the case of the cut specimens, the predominant wall effect is observed along the X-direction of the beam. This is also the main flowing direction, favouring a higher fibre contribution in this direction. Nevertheless, in the case of moulded specimens, the wall-effect imposed by the formwork and the distance of flow in $\mathrm{X}$ and in $\mathrm{Y}$ should be practically identical. Consequently, similar contributions are observed.

The influence of the content of SF on the orientation of each type of specimen is exhibited in Fig. 7. As expected, the content of fibres showed no significant influence on the orientation. This is reasonable since the same mixing and casting process was used. Moreover, the trend in the orientation is similar to the previously described in Table 3. 


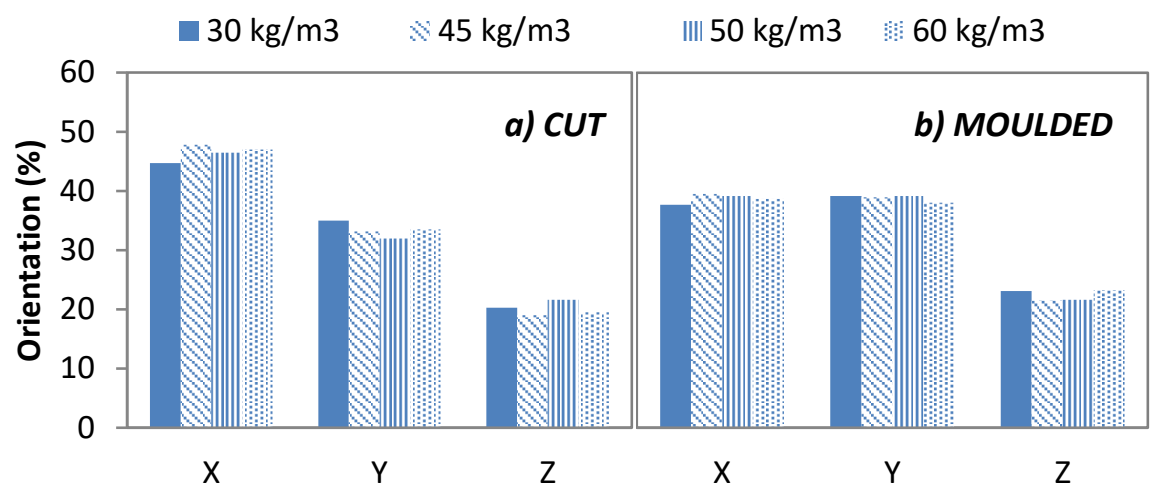

299

Fig. 7. Orientation of fibres according to the content in a) cut and b) moulded specimens.

Fig. 8.a and 8.b show the average residual strength for the dosages with $50 \mathrm{~kg} / \mathrm{m}^{3}$ of steel fibres (SCC_L60_SF_50A, SCC_L60_SF_50B,SCC_L60_SF_50C and SCC_H60_SF_50) and $3.5 \mathrm{~kg} / \mathrm{m}^{3}$ of plastic fibres (SCC_L60_PF1_3.5A and SCC_L60_PF1_3.5B), respectively. Other mixes present similar results. The grey curves show the average strength of each dosage depending on the type of specimen. The red curves represent the average strength of all dosages separated by cut or moulded samples.

No significant difference between the moulded and cut specimens was expected in the mechanical results since in both cases approximately $80 \%$ of the fibres are aligned in the XY plane. The curves confirm the small differences in terms of the average residual strength regardless of the type of fibre used. A slightly bigger scatter is observed in the cut specimens, which is in line with the higher $\mathrm{CV}$ found in the fibre contribution for

316 the latter in Table 3. The results suggest that the average mechanical results obtained

317 between moulded and cut samples are similar enough to use both types of specimens in the correlation analysis. 

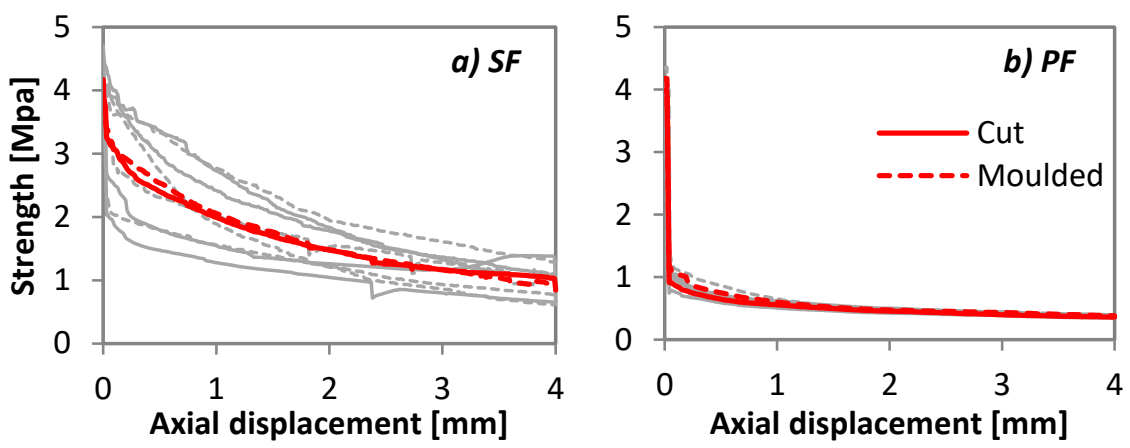

Fig. 8. Residual strength with BCN in cut and moulded specimens with a) SF and b) PF.

\section{CORRELATIONS}

\subsection{Correlation depending on variables and test parameters}

In this section a linear regression is performed between different parameters from the tests to identify those that provide the highest correlation degrees. Besides identifying the parameters that provide the best correlation, the aim is to determine whether a general correlation is possible or if it is necessary to derive specific formulations depending on the type of concrete or of fibre used.

The average stress and the average tenacity of each concrete mix were calculated for reference displacement values. For the 3PBT, the CMOD of 0.5, 1.5, 2.5 and $3.5 \mathrm{~mm}$ were taken as a reference. In the case of the $\mathrm{BCN}$, the axial displacements of $0.5,1.5$, 2.5 and $3.5 \mathrm{~mm}$ from the beginning of the test and also after cracking were taken as a reference. The nomenclature used to refer to each parameter starts with the letter "F" for forces and " $E$ " for energy values. Then, either "bcn" or "3pbt" is appended as a subscript depending on the test. The corresponding CMOD or axial displacement is 
placed at the end as a subscript. For example, $E_{b c n, 1.5}$ represents the energy estimated in the $\mathrm{BCN}$ for an axial displacement up to $1.5 \mathrm{~mm}$ after cracking.

342

343 Correlations were performed with every possible combination of one parameter of the

$3443 \mathrm{PBT}$ and one parameter of the $\mathrm{BCN}$. This procedure was repeated considering all data

345 from the experimental program or by grouping the data by rheology (conventional or self-compacting concrete), by strength class (smaller than $60 \mathrm{MPa}$ or bigger than 60) and type or content of fibre. To simplify the analysis of the results, the minimum, the maximum and the average correlation degrees were calculated for all possible combinations with each parameter of the BCN. Fig. 9 shows a summary of the coefficients of determination $\left(\mathrm{R}^{2}\right)$ obtained for $\mathrm{F}_{\mathrm{bcn}, 0.5}, \mathrm{~F}_{\mathrm{bcn}, 1.5}$ and $\mathrm{E}_{\mathrm{bcn}, 1.5 \text {, which were }}$ the parameters that showed the highest correlation degree in the linear correlation among all the analysed parameters. These represent the load and the energy obtained in the $\mathrm{BCN}$ for axial displacements of 0.5 and $1.5 \mathrm{~mm}$ measured after cracking.

The analysis shows a significant variability in $\mathrm{R}^{2}$. When all data are considered, the average $\mathrm{R}^{2}$ is approximately 0.60 , represented in a dashed line in Fig. 9. This is also true for all correlations performed when the results are grouped by rheology. Notice that the average calculated for conventional concrete is the same as that for self-compacting concrete. This suggests that the results from both concrete types may be considered indistinctly in the same formulation without compromising $\mathrm{R}^{2}$. Despite that, it is noteworthy that the scatter in $\mathrm{R}^{2}$ is twice as high in the conventional concrete than in self-compacting concrete. 


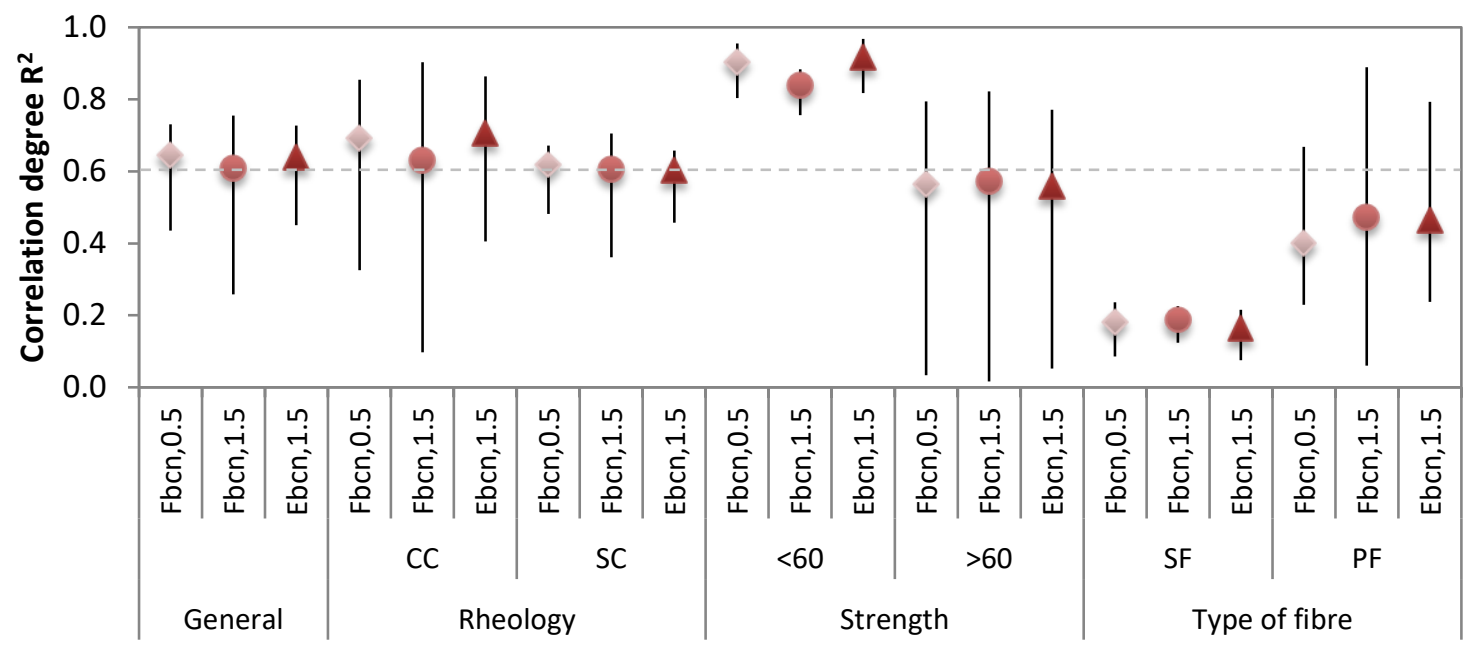

Fig. 9. Results of linear correlation analysis.

Significant differences are observed when the data is grouped by strength class. In the case of mixes with compressive strength below $60 \mathrm{MPa}$, average $\mathrm{R}^{2}$ values close to 0.90 are obtained. This improvement with regards to the general correlation is compensated by a smaller average $\mathrm{R}^{2}$ in the mixes with compressive strength above $60 \mathrm{MPa}$. Moreover, a higher variability is observed in this last group. Based on these results, the definition of separate correlations is not justified since the improvement observed would be minor.

375 The grouping by fibre type shows lower average values of $\mathrm{R}^{2}$ for steel fibre than for plastic fibre. Such outcome may be attributed to the wider range of contents tested in the former, which varies from 3.5 to $25 \mathrm{~kg} / \mathrm{m}^{3}$. This contrasts with the range of steel fibres that goes from $30 \mathrm{~kg} / \mathrm{m}^{3}$ to $60 \mathrm{~kg} / \mathrm{m}^{3}$. Despite the difference in terms of average values, the variability in the results of the $\mathrm{R}^{2}$ calculated in plastic fibre is several times bigger, presenting values that are close to those of steel fibre. 
382 It is important to remark that the average $\mathrm{R}^{2}$ obtained after grouping the fibres by type is

383 smaller than that of the general correlation. Again, this indicates that the separate

384 consideration is not justified since it would not contribute to a better correlation in the

385 case of the present experimental program. Therefore, a general correlation applicable to

386 all types of concrete, types and contents of fibre is proposed in the next section.

\subsection{Proposal of correlation}

389

390

391

An in-depth analysis was performed to identify the equation that provides the best

correlations between the $\mathrm{BCN}$ and the $3 \mathrm{PBT}$. In order to increase $\mathrm{R}^{2}$ values, a

392

multivariable regression was performed. The outcome of the equation should be a

393

parameter of the 3PBT, whereas the input should consist of parameters of the $\mathrm{BCN}$ or

394

other characteristics of the concrete. After several regressions, it was found that the best

395

correlations relate the force measured for a certain value of CMOD in the 3PBT with

the force and the energy for the same axial displacement measured in the BCN. Eq. 1

397 shows the equation proposed as a result of the regression study.

398

$$
F_{3 P B T, i}=a \cdot F_{B C N, i}+b \cdot E_{B C N, i}^{2}
$$

400 In this equation, the terms $a$ and $b$ are constants obtained in the regression for a CMOD and an axial displacement of $i$. The values of both constants and of the $\mathrm{R}^{2}$ are presented in Table 4. The $i$ corresponding to $0.5 \mathrm{~mm}$ is not included in the table since in this case

403 it was not possible to identify an acceptable correlation between tests. This may be 404 attributed to the differences in terms of crack formation in both tests, whose influence is 

not find good correlations between tests at low levels of deformation.

407

\begin{tabular}{llllll}
\hline $\boldsymbol{i}(\mathbf{m m})$ & $\boldsymbol{a}$ & $\boldsymbol{b}$ & $\begin{array}{l}\mathbf{C I}_{\mathbf{9 9} \%} \\
(\mathbf{k N})\end{array}$ & $\mathbf{R}$ & $\mathbf{R}^{2}$ \\
\hline 1.5 & $1.76 \mathrm{E}-01$ & $-3.29 \mathrm{E}-04$ & 2.00 & 0.86 & 0.74 \\
2.5 & $1.45 \mathrm{E}-01$ & $4.70 \mathrm{E}-06$ & 1.67 & 0.89 & 0.79 \\
3.5 & $1.52 \mathrm{E}-01$ & $1.46 \mathrm{E}-05$ & 1.65 & 0.87 & 0.76 \\
\hline
\end{tabular}

408

Table 4. Constants and confidence interval of Eq. 2.

409

410 Fig. 10 shows the comparison between the results obtained from 3PBT and the

411 corresponding result estimated for the same mix with Eq. 1 from the results of the BCN

412 for the displacements $i$ of 1.5, 2.5 and $3.5 \mathrm{~mm}$. The straight line indicates the

equivalence line. The predictions made with Eq. 1 approaches the results from the 3PBT increases, so does the goodness of the predictions made with the correlation.

416

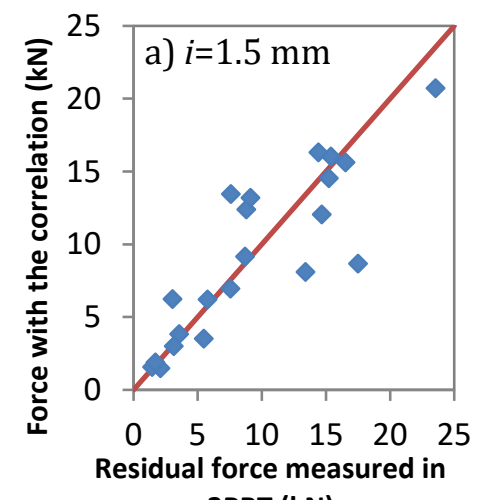

3PBT (kN)

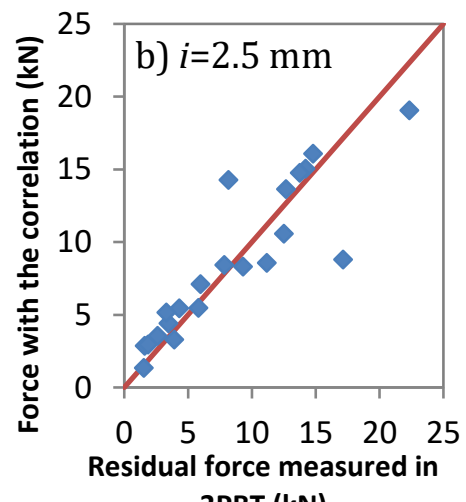

3PBT (kN)

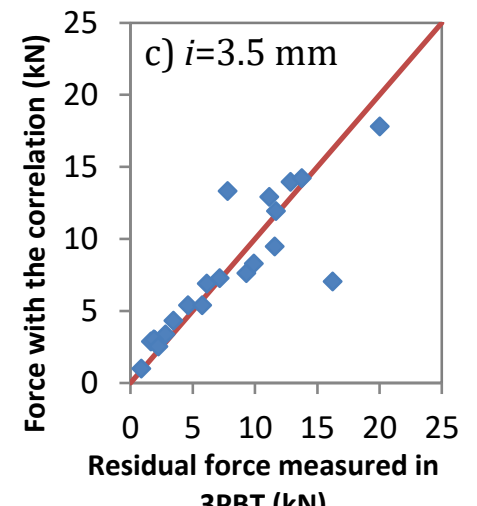

3PBT (kN)

Fig. 10. Comparison between force measured in the 3PBT and force estimated from the 


\subsection{Confidence intervals}

423

424 A natural variability of results should be expected when applying either the 3PBT or the

BCN. This variability should also affect the correlations obtained. In certain practical situations, it might be interesting to consider a safety margin capable of compensating at least part of the uncertainty in the prediction of the results of one test. A statistical analysis of the results from Fig. 10 was conducted with the aim of assessing confidence intervals for the correlation proposed.

430

431 First, the Kolmogorov-Smirnov test was applied to determine whether the error in the

432 predictions from Eq. 1 with regards to the experimental results follow a normal

433 distribution. Once the normality was verified, the confidence interval of $99 \%\left(\mathrm{CI}_{99 \%}\right)$

434 presented in table 4 were calculated for the displacements $i$ of 1.5, 2.5 and $3.5 \mathrm{~mm}$. The predicted value of the 3PBT considering the safety margin should be calculated according with Eq. 2.

437

$$
F_{3 P B T, i}=a \cdot F_{B C N, i}+b \cdot E_{B C N, i}^{2}-C I_{99 \%, i}
$$

\section{$439 \quad 5.4 \quad$ Verification of the results}

The formulation obtained in the parametric study is here compared with the experimental results of the 3PBT for all dosages. Fig. 11 shows several results of the Load-CMOD for both the experimental data (3PBT) in a solid line and the results 444 calculated by means of the correlation proposed (Cor) in a dashed line. The points of the 
446 lower confidence interval corresponding to each CMOD.
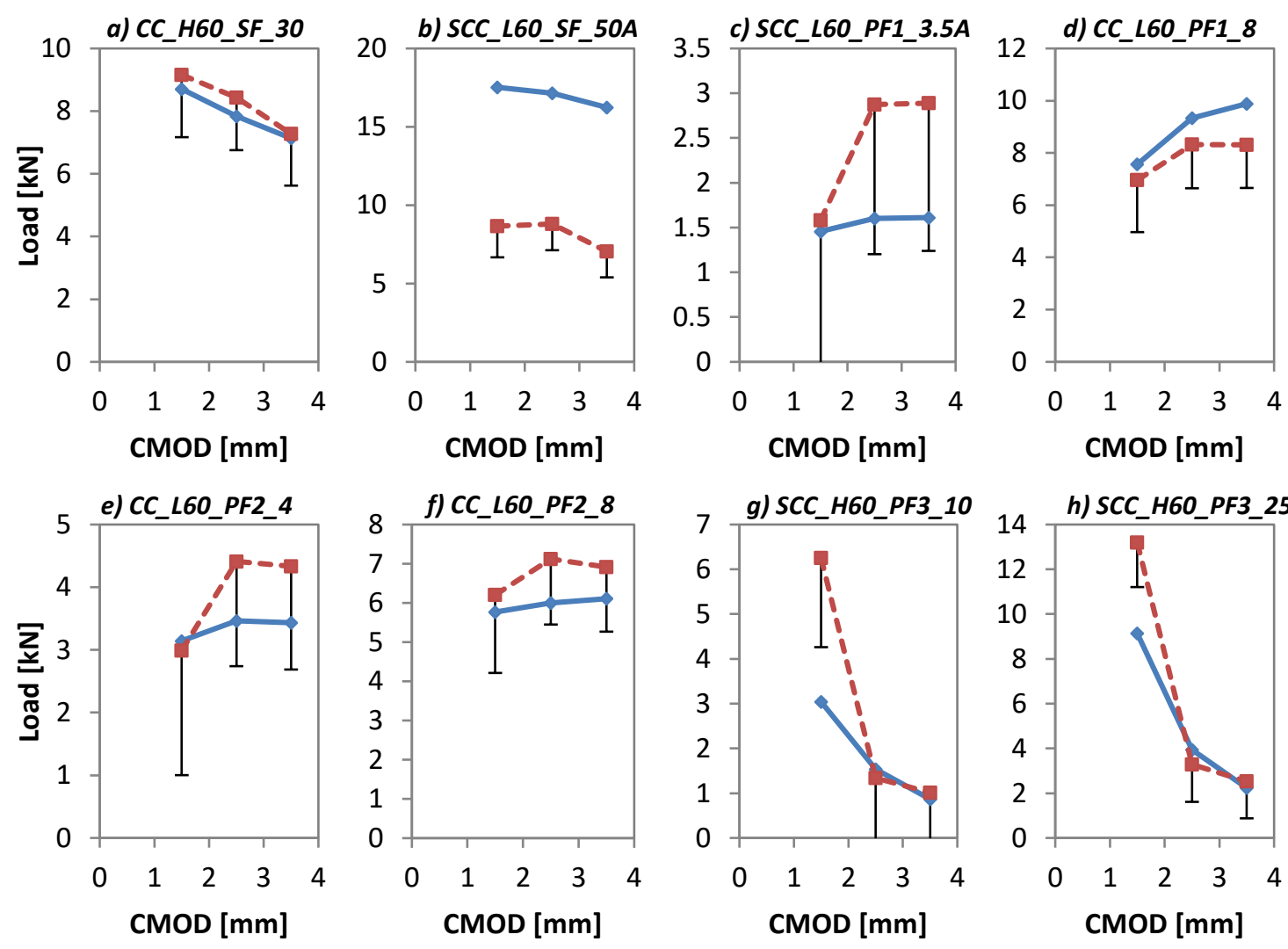

Fig. 11. Real and predicted curves of $3 P B T$ with confidence intervals.

A general overview of the results shows that the calculated curves follow similar trends to those obtained directly from the 3PBT. In the great majority of cases the values measured during the 3PBT are found above the limit defined by the confidence intervals. The only composition in which this is not fulfilled for all displacements is the SCC_H60_SF_60. This confirms that the safety margin introduced is capable of compensating the errors of the predictions.

457 The accuracy of the prediction decreases with the load level. In certain cases, negative values of the confidence lower limit are obtained. This should be expected when the 
force measured during the 3PBT are below $5 \mathrm{kN}$, being especially evident in some of the mixes with plastic fibres.

461

\section{CONCLUSIONS}

463

The approach proposed in this study showed that it is possible to predict the 3PBT based on the results of the $\mathrm{BCN}$ with a confidence margin, despite the wide variety of fibre type, fibre content and rheology considered. This opens up the possibility of using the $\mathrm{BCN}$ as a complementary test for the systematic quality control of FRC. The same approach may be applied to correlate other tests or to obtain better correlations for specific types of FRC. The following conclusions may be derived based on the results and the analysis presented here. $\mathrm{BCN}$. This difference is mainly attributed to the cracking mechanism that takes place in each test. In the $\mathrm{BCN}$, the cracks form abruptly. The load resisted by the cementitious matrix is almost instantaneously transferred to the fibre. Conversely, in the 3PBT the crack height tends to increase progressively, yielding a more gradual load transfer from the matrix to the fibres in the area subjected to tension.

- The correlation between the 3PBT and the BCN considering only one parameter of each test did not provide acceptable results. In order to improve the correlation degree, it is advisable to include more than one parameter in the regression. In the present study, the parameters that yielded the best fits were the force and the energy measured for a certain axial displacement in the $\mathrm{BCN}$, which are related with the force measured in the 3PBT. 
497

502

503

504

505

506

- Only one equation (Eq. 2) is needed to correlate the 3PBT and the BCN, regardless of the type of fibre, the content of fibre or the rheology of concrete. The correlation degrees $\left(\mathrm{R}^{2}\right)$ achieved range from 0.70 and 0.75 depending on the CMOD. It is important to remark that for low CMOD values, the correlation with the BCN may not be possible due to the differences in terms of the crack formation in both tests.

- Almost all experimental measurements with the 3PBT remain above the prediction with the confidence interval using the results from the BCN. This confirm that the use of confidence intervals is an interesting approach to obtain prediction on the safe side for a material subjected to significant scatter, such as FRC.

\section{ACKNOWLEDGEMENTS}

The authors wish to express their gratitude to the Spanish Ministry of Economy and Competitiveness for the financial support in the scope of the project DURADOV (reference: RTC-2015-3617-4). The first author also thanks the Spanish Ministry of Education, Culture and Sport for the FPU13/04864 grant.

\section{REFERENCES}

[1] Cavalaro SHP, Aguado A. Intrinsic scatter of FRC: an alternative philosophy to estimate characteristic values. Mater Struct 2015;48(11):3537-3555. 
507 [2] CEN (European Committee for Standardization). EN 14651:2007: Test method 508 for metallic fibre concrete. Measuring the flexural tensile strength (limit of 509 proportionality (LOP), residual). Brussels, 2007.

510 [3] Parmentier B, Grove E De. Dispersion of the mechanical properties of FRC 511 investigated by different bending tests. Tailor Made Concr. Struct 2008.

512 [4] Molins C, Aguado A, Saludes S. Double Punch Test to control the energy 513 dissipation in tension of FRC (Barcelona test). Mater Struct 2008;42(4):415-425.

514 [5] NBN (Bureau de Normalisation). B 15-238. Test on fibre reinforced concrete 515 bending test on prismatic samples. Norme Belge, Institut Belge de Normalisation, 516 Brussels 1992.

517 [6] Löfgren I, Stang H, Olesen JF. Fracture Properties of FRC Determined through 518 Inverse Analysis of Wedge Splitting and Three-Point Bending Tests. J Adv Concr 519 Technol 2005;63(3):423-434.

520 [7] Prisco M, Lamperti MGL, Lapolla S. Double-edge wedge splitting test:

521 preliminary results. In: Fracture Mechanics of Concrete and Concrete Structures

522 (FraMCoS-7). Jeju (S. Korea), 2010. p. 1579-1586.

523 [8] Prisco M, Ferrara L, Lamperti MGL. Double edge wedge splitting (DEWS): an 524 indirect tension test to identify post-cracking behaviour of fibre reinforced cementitious 525 composites. Mater Struct 2013;46(11):1893-1918.

526 [9] Model Code 2010. fib Fédération Internationale du Béton, 2010.

527 [10] Perumal R. Correlation of Compressive Strength and Other Engineering 528 Properties of High-Performance Steel Fiber-Reinforced Concrete. J Mater Civ Eng $529 \quad 2015 ; 27(1): 1-8$. 
530 [11] Minelli F, Plizzari, G. Fiber reinforced concrete characterization through round panel test - Part I: experimental study. In: Fracture Mechanics of Concrete and Concrete 532 Structures (FraMCoS-7). Jeju (S. Korea), 2010. p. 1451-1460.

533 [12] Abrishambaf A, Barros JAO, Cunha VMCF. Tensile stress-crack width law for 534 steel fibre reinforced self-compacting concrete obtained from indirect (splitting) tensile 535 tests. Cem Concr Compos 2015;57:153-165.

536 [13] Minelli F, Plizzari G. Derivation of a simplified stress-crack width law for Fiber 537 Reinforced Concrete through a revised round panel test. Cem Concr Compos $538 \quad 2015 ; 58: 95-104$.

539 [14] AENOR (Asociación Española de Normalización y Certificación). UNE 83515. 540 Fibre reinforced concrete. Determination of cracking strength, ductility and residual 541 tensile strength. Barcelona test. Madrid, 2010.

542 [15] Pujadas P, Blanco A, Cavalaro SHP, de la Fuente A, Aguado A. Multidirectional 543 double punch test to assess the post-cracking behaviour and fibre orientation of FRC.

544 Constr Build Mater 2014;58:214-224.

545 [16] Pujadas P, Blanco A, Cavalaro S, de la Fuente A, Aguado A. New Analytical 546 Model To Generalize the Barcelona Test Using Axial Displacement. J Civ Eng Manag $547 \quad 2013 ; 19(2): 259-271$.

548 [17] Blanco A, Pujadas P, Cavalaro S, de la Fuente A, Aguado A. Constitutive model 549 for fibre reinforced concrete based on the Barcelona test. Cem Concr Compos $550 \quad 2014 ; 53: 327-340$.

551 [18] Stähli P, Custer R, Mier JGM. On flow properties, fibre distribution, fibre 552 orientation and flexural behaviour of FRC. Mater Struct 2007;41(1):189-196. 
553 [19] Ferrara L, Ozyurt N, di Prisco M. High mechanical performance of fibre

554 reinforced cementitious composites: the role of 'casting-flow induced' fibre orientation.

555 Mater Struct 2010;44(1):109-128.

556 [20] Boulekbache B, Hamrat M, Chemrouk M, Amziane S. Flowability of fibre-

557 reinforced concrete and its effect on the mechanical properties of the material. Constr

$558 \quad$ Build Mater 2010;24(9):1664-1671.

559 [21] Kang ST, Lee BY, Kim JK, Kim YY. The effect of fibre distribution

560 characteristics on the flexural strength of steel fibre-reinforced ultra high strength

561 concrete. Constr Build Mater 2011;25(5):2450-2457.

562 [22] Zerbino R, Tobes JM, Bossio ME, Giaccio G. On the orientation of fibres in

563 structural members fabricated with self compacting fibre reinforced concrete. Cem

564 Concr Compos 2012;34(2):191-200.

565 [23] Abrishambaf A, Barros JAO, Cunha VMCF. Relation between fibre distribution

566 and post-cracking behaviour in steel fibre reinforced self-compacting concrete panels.

567 Cem Concr Res 2013;51:57-66.

568 [24] CEN (European Committee for Standardization). EN 12390-3. Testing hardened

569 concrete. Part 3: Compressive strength of test specimens. Brussels, 2009.

570 [25] Torrents JM, Blanco A, Pujadas P, Aguado A, Juan-García P, Sánchez-

571 Moragues MA. Inductive method for assessing the amount and orientation of steel

572 fibers in concrete. Mater Struct 2012;45(10):1577-1592.

573 [26] Cavalaro SHP, López R, Torrents JM, Aguado A. Improved assessment of fibre

574 content and orientation with inductive method in SFRC. Mater Struct 2015;48(6):1859-

5751873.

576 [27] Barros JAO, Cunha VMCF, Ribeiro AF, Antunes JAB. Post-cracking behaviour

577 of steel fibre reinforced concrete. Mater Struct 2005;38(1):47-56. 
578 [28] Sivakumar A, Santhanam M. Mechanical properties of high strength concrete

579 reinforced with metallic and non-metallic fibres. Cem Concr Compos 2007;29(8):603580608.

581 [29] Buratti N, Mazzotti C, Savoia M. Post-cracking behaviour of steel and macro-

582 synthetic fibre-reinforced concretes. Constr Build Mater 2011;25(5):2713-2722.

583 [30] Soutsos MN, Le TT, Lampropoulos AP. Flexural performance of fibre

584 reinforced concrete made with steel and synthetic fibres. Constr Build Mater $585 \quad 2012 ; 36: 704-710$.

586 [31] Alberti MG, Enfedaque A, Gálvez JC. On the mechanical properties and fracture 587 behavior of polyolefin fiber-reinforced self-compacting concrete. Constr Build Mater $588 \quad 2014 ; 55: 274-288$.

589 [32] Wille K, El-Tawil S, Naaman AE. Properties of strain hardening ultra high 590 performance fiber reinforced concrete (UHP-FRC) under direct tensile loading. Cem 591 Concr Compos 2014;48:53-66.

592 [33] Edgington J, Hannant DJ. Steel fibre reinforced concrete. The effect on fibre 593 orientation of compaction by vibration. Mater Struct 1972;5(1):41-44.

594 [34] Martinie L, Roussel N. Simple tools for fiber orientation prediction in industrial 595 practice. Cem Concr Res 2011;41(10):993-1000.

596 [35] Wille K, Tue NV, Parra-Montesinos GJ. Fiber distribution and orientation in 597 UHP-FRC beams and their effect on backward analysis. Mater Struct $598 \quad 2013 ; 47(11): 1825-1838$.

599 [36] Bernard ES. Correlations in the behaviour of fibre reinforced shotcrete beam and 600 panel specimens. Mater Struct 2002;35(3):156-164. 